\section{An anthropological insight into the Pacific island diabetes crisis and its clinical implications}
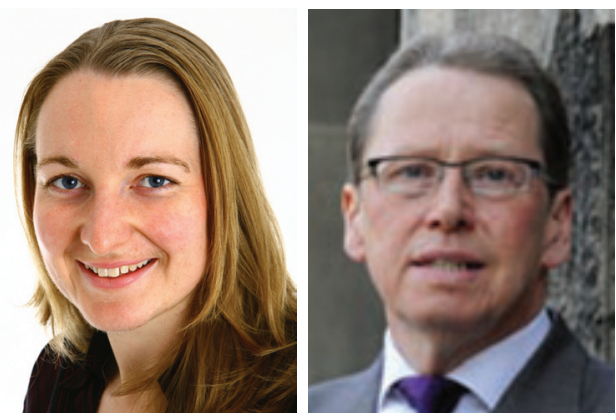

"Better understanding of how social connections and social histories relate to diabetes would help in addressing the diabetes crisis in the Pacific island region.”

Amy K McLennan* ${ }^{* 1}$ \& Stanley J Ulijaszek ${ }^{1}$

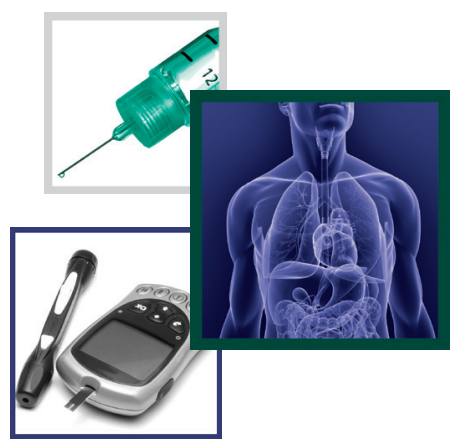

\section{Diabetes in the Pacific islands}

The prevalence of Type 2 diabetes mellitus (hereafter 'diabetes') in Pacific Island Countries and Territories (PICTs) is higher than that reported for Asia, Africa and the Middle East [1]. This is not a new development; rather, research carried out in PICTs was central to diabetes initially appearing on epidemiological and public health agendas more generally. At the European Association for the Study of Diabetes meeting in Helsinki, 1976, Paul Zimmet warned the world about a looming epidemic of diabetes [2]. His warning was based on an epidemiological survey he and his team had just carried out on the small Pacific island nation of Nauru. Over $30 \%$ of the adult population tested was diagnosed with diabetes. The team subsequently carried out surveys in other PICTs, and identified similar patterns of diabetes across the region.

Despite almost 40 years of public health and clinical attention, diabetes prevalence remains high in many parts of the region, including in Nauru (49\% of adults aged 40 years and above have been diagnosed with diabetes) and some peoples of Papua
New Guinea (48.7\% of Wanigela people aged 25 years and above have been diagnosed with diabetes) [1]. PICTs remain a 'litmus test for how both small island developing states and the global community respond to the crisis in noncommunicable diseases' [3] such as diabetes.

It is widely understood that the "development of diabetes in PICTs is closely related to rapid economic and urban development over recent decades" [1]. However, clinical approaches to date have largely focused on addressing the individual patient, internal physiological processes, and the eating and activity behaviors which drive these processes. Anthropological attention brings focus back onto factors such as rapid economic and urban development, and considers how these impact health by affecting people's everyday ways of life.

Anthropological research focuses on society, and the way in which people are entangled in networks of social, political and economic forces and relationships. These networks are not fixed over time, but are constantly changing; history, especially historical change prior to diabetes

'School of Anthropology \& Museum Ethnography, University of Oxford, 51/53 Banbury Road, Oxford, OX2 6PE, UK

\section{KEYWORDS}

- anthropology • diabetes $\bullet$ lifestyle - social networks $\bullet$ noncommunicable diseases $\bullet$ Pacific islands $\bullet$ social connections $\bullet$ social history

"We have experienced first-hand the devastating impacts that such diseases have on individuals, families and communities in some Pacific Island Countries and Territories." 
“Interventions that target individuals as the locus of change have the potential to be harmful." emergence or onset, is important. In our research, we are interested in how these dynamic forces and relationships drive demographic health change through shaping the world and the habits of people living in it. For this reason, anthropologists have the potential to contribute new perspectives.

Anthropological research is informed by long periods of fieldwork, typically months or years, working with people in a local setting. It is inductive rather than deductive [4]. The method of participant observation means that anthropologists are to some extent participants within the communities they study but are simultaneously removed from them; this gives anthropologists unique insights into how life feels to people on a daily basis, and the (often competing) forces and relationships that affect the lives of people every day. Other methods, including tests, surveys and interviews, inform and enrich ethnographic approaches, allowing inductive investigation of broad themes or ideas, including those of how diabetes and other nutrition-related noncommunicable diseases shape and are shaped by people's lives.

During our research fieldwork to date, we have experienced first-hand the devastating impacts that such diseases have on individuals, families and communities in some PICTs. We have also observed different attempts to prevent and treat diabetes, and heard reactions and responses to them on a daily basis. Our fieldwork research is specific to certain PICTs, particularly the Cook Islands (Ulijaszek, 9 months), Papua New Guinea (Ulijaszek, 40 months) and Nauru (McLennan, 11 months). While it is important to avoid essentializing the Pacific islands and the people who live on them, as they have unique and varied social lives and social histories, our research can inform thinking about diabetes aetiology more broadly. Here, we offer one anthropological perspective based on our observations, and sketch three points of potential relevance to clinicians.

\section{History \& social change are important}

The isolation of an individually-assessed patient in a clinic belies their social interconnectedness. Each patient has a family, a local community, and perhaps belongs to a clan or church group, for example. Communities, in turn, form part of an island or nation, which is connected in myriad ways (from ancient trade routes to global media) to the rest of the world. The social histories of diabetes patients extend before the time of diagnosis; their communities have histories which extend into the past well beyond any one individual's life. Such histories are connected with the histories of other places and people [5]. This has implications for understanding factors that underlie diabetes etiology. It also has implications for designing effective interventions. If lifestyle patterns, for example, develop over time and are embedded in social behaviors, they are unlikely to change immediately following clinical advice. Nor are they likely to change if the social networks - both local and global - in which they are embedded do not change. With this in mind, encouraging change only among those clinically diagnosed with diabetes is unlikely to be effective.

Social connections matter because they shape everyday habits. Anthropologists have shown how food and eating are integral to maintaining social connections in places such as the Cook Islands [6]. Others working in Fiji have shown how social values about body size can change in the course of a single generation, as a result of globalizing technologies such as television [7]. Certain brands or products can be associated with status, for example, fatty cuts of meat or instant noodles in Papua New Guinea [8,9]. Consuming such foods is thus not simply about sensory pleasure, but about social approval. This may be especially important for otherwise marginalized peoples. Social connections also matter because they shape the environments in which people live. Trade policies and market forces, for instance, have been major drivers of dietary change in PICTs [10]. In such globally social networks, unequal power relations often lead to unequal health outcomes.

Interventions that target individuals as the locus of change have the potential to be harmful. They can lead to a sense of disempowerment, especially if people understand they should consume certain foods but cannot, because recommended foods are unaffordable, unavailable and/or are not as much of a priority as other things. Such interventions also have the potential to result in social isolation or stigmatization, both of which have negative health impacts $[11,12]$. Isolation may result if dietary changes mean that individuals are no longer able to engage in activities which link friends and family together, such as feasting together or sharing food. It should be acknowledged that global communities of specialists who try to understand and address patterns of disease may be complicit in stigmatization. By way of explaining diabetes rates, the people of Nauru, for example, have been branded as 'lazy' [13] . 


\section{Clinical implications}

It is often inferred that people in PICTs make lifestyle decisions that can contribute to diabetes because they are not sufficiently educated to know what is 'healthy' for them. Yet evidence suggests otherwise: in the last major health survey carried out in Nauru, for example, the majority of respondents knew that exercise and a healthy diet are associated with reduced risk of diabetes [14]. The issue may be one of so-called adherence: people simply choose to ignore medical advice. For anthropologists who have spent considerable time in communities affected by debilitating rates of diabetes and associated amputations, blindness, low life expectancy, gangrene and dialysis, the conclusion that people might actively choose to develop diabetes seems difficult to comprehend. Indeed, most Nauruans surveyed were frightened of getting diabetes [14]. So there must be other explanations.

From an anthropological perspective, 'the individual' is a unit which is, in everyday practice, interconnected with the people and places around it. 'Lifestyle' amounts to much more than diet and physical activity, and social relationships form a significant part of it. Similarly, 'health' is a field which is, in practice, interconnected with other domains. Clinical interventions for diabetes are typically situated within individualist frameworks, and focus on the domain of health. This may be part of the problem.

Individuals are socially embedded, lifestyle patterns have long histories and health is not a separate domain. The challenge for clinicians is in working out how to incorporate these three factors when an individual patient is in consultation with them. Anthropology has shined a light on these issues, and more detailed and extensive understanding is needed among a wide range of societies. Better understanding of how social connections and social histories relate to diabetes would help in addressing the diabetes crisis in the Pacific island region.

\section{Acknowledgements}

The authors are grateful for the generous assistance, advice and support we received during fieldwork from communities in the Cook Islands, Papua New Guinea and Nauru.

\section{Financial \& competing interests disclosure}

McLennan's fieldwork and data analysis in Nauru were supported by a Monash Award (General Sir John Monash Foundation [Australia]) and a grant from St Edmund Hall (Oxford). The authors have no other relevant affiliations or financial involvement with any organization or entity with a financial interest in or financial conflict with the subject matter or materials discussed in the manuscript apart from those disclosed.

No writing assistance was utilized in the production of this manuscript.

\section{References}

- Win Tin ST, Lee CM, Colagiuri R. A profile of diabetes in Pacific island countries and territories. Diabetes Res. Clin. Pract. 107(2), 233-246 (2014).

2 Zimmet PZ. A lifetime pursuit of diabetes through chance. Med. J. Aust. 191(11-12), 632-636 (2010).

- 3 Tuitama LT, Young-soo S, Clark H, Tukuitonga C, Beaglehole R. Acting on the Pacific crisis in non-communicable diseases. Lancet 384(9957), 1823-1824 (2014).

4 Parkin D, Ulijaszek SJ. Introduction: emergence and convergence. In: Holistic Anthropology: Emergence and Convergence. Parkin D, Ulijaszek S (Eds). Berghahn Books, Oxford, UK, 1-20 (2007).

-5 McLennan AK, Ulijaszek SJ. Obesity emergence in the Pacific islands: why understanding colonial history and social change is important. Public Health Nutr. 18(8), 1499-1505 (2014).

6 Alexeyeff K. Love food: exchange and sustenance in the Cook Islands diaspora. Aust. J. Anthropol. 15(1), 68-79 (2004).

-7 Becker AE, Gilman SE, Burwell RA. Changes in prevalence of overweight and in body image among Fijian women between 1989 and 1998. Obes. Res. 13(1), 110-117 (2005).

8 Gewertz D, Errington F. Cheap Meat: Flap Food Nations in the Pacific Islands. University of California Press, CA, USA (2010).

Errington F, Fujikura T, Gewertz D. Instant noodles as an antifriction device: making the BOP with PPP in PNG. Am. Anthropol. 114(1), 19-31 (2012).
10 Snowdon W, Thow AM. Trade policy and obesity prevention: challenges and innovation in the Pacific Islands. Obes. Rev. 14(S2), 150-158 (2013).

Holt-Lunstad J, Smith TB, Layton JB. Social relationships and mortality risk: a metaanalytic review. PLoS Med. 7(7), e1000316 (2010).

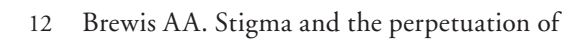
obesity. Soc. Sci. Med. 118, 152-158 (2014).

13 Diamond J. The double puzzle of diabetes. Nature 423(6940), 599-602 (2003).

14 Government of Nauru, World Health Organisation. Nauru NCD Risk Factors STEPS Report. World Health Organisation Western Pacific Region (WHO WPR), Suva (2007). www.who.int/chp/steps/Printed_STEPS 